\title{
Effects of diazepam on encoding processes
}

\author{
M. Gorissen, P. Eling, G. van Luijtelaar and A. Coenen \\ NICI, Department of Comparative and Physiological Psychology, University of Nijmegen, Nijmegen, The Netherlands
}

Benzodiazepines are known to induce amnesic effects. To specify these effects more precisely, 40 healthy volunteers were given $15 \mathrm{mg}$ diazepam or placebo. Effects on a chain of encoding operations were investigated: activation of memory representations, spreading of activation, semantic encoding and organizational processes. The diazepam group performed tasks consistently slower, although spreading of activation and semantic encoding were not affected by diazepam. Rather, diazepam subjects benefited less from opportunities to organize to-be-learned material. It is suggested that cognitive processes are slowed down after diazepam intake. This may also have implications for the organization of to-be-learned material.

Key words: diazepam; benzodiazepines; memory; semantic encoding; priming; lexical decision

\section{Introduction}

In the past decade, many studies have demonstrated that benzodiazepines (BZD) impair the acquisition of information into long-term memory, whereas short-term memory and retrieval from long-term memory are left intact (Mewaldt, Ghoneim and Hinrichs, 1986; Roy-Byrne et al., 1987; Ghoneim and Mewaldt, 1990; File, Sharma and Shaffer, 1992). In all these studies in which word lists had to be learned in a limited time, subjects recalled fewer words after BZD than after placebo intake. Some authors suggested that this memory deficit is attributable to an impairment in encoding operations employed during the acquisition phase (Frith et al., 1984; Rodrigo and Lusiardo, 1988; Stephens, Duka and Andrews, 1991). Although there have been studies into the effects of BZD on specific encoding operations, Curran (1986) claimed that no single study investigated the range of possible loci of BZD effects in the chain of encoding processes during learning. Moreover, the studies that investigated separate encoding operations are not directly comparable, because different kinds and doses of BZD were used.

The purpose of the present study is to investigate the effects of one frequently used BZD, diazepam, on a chain of different encoding operations involved in intentionally learning a word list. Unfortunately, no detailed model is available that describes all encoding operations. Different models focus on separate processes, but the models are not incompatible with each other. There is general agreement as to which encoding operations are involved in learning of word lists (see Johnson and Hasher, 1987; Johnson and Hirst, 1991). Firstly, we will describe these encoding operations and subsequently the tasks that measure these operations.

When a word is perceived, its memory representation is activated. This activation temporarily increases the availability of the word (Taft, 1991; Johnson and Hirst, 1991). Activation of a representation spreads automatically along the paths of the memory network and activates semantically related word representations (Tweedy, Lapinski and Schvaneveldt, 1977). The automatic spreading activation is fast and occurs without intention. Spreading activation can also arise from the attentional system. If expectancies are built up, the attentional system focuses attention on the expected memory representation (Neely, 1977; Posner and Snyder, 1975). Craik and Lockhart (1972) suggest that a memory trace is a direct result of the qualitative nature of encoding operations. A stimulus can be processed at different levels (i.e. depths), where depth is defined in terms of meaningfulness extracted from the stimulus. According to this levels-of-processing approach, the deeper the material is encoded, the better it will be recalled. In addition to automatic processes, strategic processes also play a role in learning a word list. The set of words to be learned has to be organized for an optimum recall (Masson and McDaniel, 1981; Johnson and Hasher, 1987). For example, organization can be based on semantic or phonological properties.

Several different tasks have been used to assess these encoding operations. If a word is presented on two successive occasions, subjects are usually faster in identifying the word on the second occasion. For example, lexical decisions (e.g. word-non-word decisions) are faster for repeated words; this is called the repetition priming effect. It is unknown whether this effect is exclusively due to activation of semantic memory or whether it also reflects episodic learning (Feustel, Shiffrin and Salasoo, 1983). However, whatever the explanation for this may be, it reflects the fact that a word is more accessible after repetition. A smaller or even no repetition effect is generally found for non-words in lexical decision tasks. We used a repetition priming task to investigate whether representations in memory are temporarily activated after diazepam ingestion.

A lexical decision is made faster when a word (the 'target') follows a semantically related word, the 'prime'. This phenomenon is called semantic priming. When a prime (e.g. 'bread') is consciously perceived, the subject may anticipate, i.e. he or she strategically activates potential word representations. Recognition of an expected target (e.g. 'butter') is facilitated, 
but recognition is delayed for an unexpected target (e.g. 'dog'). The latter phenomenon is called the 'inhibition effect'. A strategic semantic priming task was used in which the probability of related prime-target pairs is high and the interval between prime and target was long. This task was used in order to investigate spreading activation that arises from the attentional system. A second semantic priming task was used in which the prime was masked and in which prime-target intervals were very brief. In this task the prime could not be consciously perceived and no expectancy could be built up. This latter task was used in order to assess automatic spreading activation.

Superficial processing of newly learned words, due to a disruption of semantic encoding, might be another reason for impaired learning. However, if subjects who ingested diazepam do pay attention to semantic features, their recall and recognition should be better for semantically encoded words compared to orthographically and phonologically encoded words. Therefore a levels-of-processing task was used to investigate semantic encoding.

Memory for word lists has been shown to depend upon mnemonic organization; recall is better for word lists that can be organized in semantic categories, compared to random word lists (Bousfield, 1953). If diazepam affects semantic encoding, subjects should not benefit from word lists that can be organized in semantic categories. A sequence consisting both of unrelated words and of groups of semantically related words was presented. Not only recall but also the extent of category clustering was used as an index of organization (Murphy, 1979).

In order to find out whether subjects had memory problems after diazepam intake, one word list was presented before and one after substance ingestion, as was done in previous studies (Brown et al., 1982; Coenen et al., 1989; Danion et al., 1990). Diazepam impairs transfer into long-term memory but leaves retrieval intact (Ghoneim and Mewaldt, 1990). Therefore, postdrug list recall should be impaired, but recall for the pre-drug word list should be better for the diazepam group than for the placebo group. This effect has often been reported and is explained by a reduced interference of the post-drug words in the diazepam group (Ghoneim and Mewaldt, 1990). Rate of forgetting, as measured by means of recall at different intervals after list presentation, should not differ between the diazepam and placebo group, since consolidation is not affected by BZD (Brown, Brown and Bowes, 1983).

Retrieval from semantic memory has been investigated using a word fluency task. Apart from number of words produced, the time to produce these words has also been measured. Stephens, Duka and Andrews (1991) assume that slowing down of information processing is a central aspect of BZD effects, therefore a longer time to perform the fluency task was expected, but no difference in the number of produced words (Mewaldt, Ghoneim and Hinrichs, 1986; Curran, Schiwy and Lader, 1987).

BZD are known to impair Jsychomotor performance (Matilla, Matilla and Aranko, 1988) and produce drowsiness. These non-specific effects may also affect memory processes. Psychomotor performance and mood were investigated using a choice reaction time task and a mood questionnaire to investigate whether the subjects remained alert after diazepam intake.

\section{Method}

\section{Subjects}

Forty healthy psychology students who complied with the relevant medical exclusion criteria participated in this study. They fulfilled a psychology course requirement. Mean age was 23 years and ranged from 19 to 33 . Written informed consent was given by all subjects. They were randomly assigned to either diazepam or placebo treatment and there was an equal number of males and females per condition.

\section{Procedure}

Subjects were instructed to refrain from beverages containing alcohol and from psychoactive drugs for a period of $24 \mathrm{~h}$ before testing. Subjects were requested to take a light fat-free breakfast on the morning of the experiment and to arrive at the laboratory at $9.00 \mathrm{~h}$. Coffee, tea and smoking were not permitted on the testing day. Diazepam $(15 \mathrm{mg})$ or placebo were administered orally in a double-blind fashion and testing started $1 \mathrm{~h}$ after substance administration. The order of the tasks was fixed for all subjects. Table 1 summarizes the tasks. The order of administration of the tasks was chosen in such a way that interference between tasks was minimized. Furthermore, the reaction time tasks were spread over the entire test session.

\section{Material}

\section{5-Word lists}

Two word lists with 15 nouns were selected. These were matched for word frequency (Uit den Boogaart, 1975), number of syllables and imagery (Van Loon-Vervoorn, 1985). One list was presented pre-drug, the other post-drug. Order of list presentation (I or II) was counterbalanced across subjects. Words were presented auditorally. Subjects were asked to recall the words immediately after presentation. After 10 and $30 \mathrm{~min}$, subjects were again requested to recall as many words as possible. A non-verbal figure task was used as a filler-task between the immediate and 10 min delayed recall. This task was not relevant to the

Table 1 Order of presentation of the tasks

\begin{tabular}{|c|c|}
\hline $\operatorname{Time}^{\mathbf{a}}$ & Name of task \\
\hline $\begin{array}{l}-40 \\
-30\end{array}$ & $\begin{array}{l}\text { 15-word list presentation and direct recall } \\
\text { (filler task between the immediate and } 10 \mathrm{~min} \\
\text { delayed recall) }\end{array}$ \\
\hline-20 & Profile of mood states \\
\hline-15 & Word fluency and pause \\
\hline-5 & Delayed $(30 \mathrm{~min})$ recall 15 -word list \\
\hline 0 & Drug or placebo administration \\
\hline 60 & Levels-of-processing task \\
\hline 75 & Automatic semantic priming task \\
\hline 90 & 15-word list presentation and direct recall \\
\hline 100 & $\begin{array}{l}\text { (filler task between the immediate and } 10 \mathrm{~min} \\
\text { delayed recall) }\end{array}$ \\
\hline 110 & Profile of mood states \\
\hline 115 & Choice reaction time task \\
\hline 125 & Delayed $(30 \mathrm{~min}$ ) recall 15 -word list \\
\hline 130 & Organized word lists \\
\hline 140 & Strategic semantic priming task \\
\hline 165 & Word fluency \\
\hline 170 & Repetition priming task \\
\hline 190 & Recall of pre- and post-drug 15 -word lists I and II \\
\hline
\end{tabular}

${ }^{a}$ Minutes from drug administration to the beginning of each test. 
assessment of memory and results will not be reported here. Subjects were asked to recall as many words as possible from the pre-drug list, and subsequently from the post-drug list, at the end of the experiment.

\section{Repetition priming task}

Two stimulus lists, A and B, each consisted of $\mathbf{3 0}$ words and 30 pseudowords (non-words that are orthographically permissible Dutch letter sequences). A third list (C) contained 60 words and 60 pseudowords. Half of these words were taken from list A and half from list B. Subjects were presented first with list $\mathbf{A}$ and then with list $\mathrm{C}$, or first list $\mathrm{B}$ and then list $\mathrm{C}$. Thus, at the presentation of list $C$, half of the words and pseudowords were new, and half of them had been presented before. Stimuli were presented individually on a computer screen. A trial started with the presentation of a fixation star for $100 \mathrm{~ms}$, which was immediately replaced by the stimulus. Subjects were instructed to press the yes-button when a stimulus was a legal Dutch word, or the no-button when a pseudoword was presented. Both speed and accuracy were stressed in the instructions. Reaction time and responses were registered. After every block of 15 trials, feedback was given about number of errors and mean reaction time (RT). The presentation of the lists ( $A$ and $C$ or $B$ and $C$ ) was separated by a brief rest period of 5 min. All lists were preceded by 15 practice trials.

\section{Automatic semantic priming task}

The materials and procedure were taken from a study reported by De Groot (1983). There were three groups of prime-word pairs (120 in total): one group of related, one group of unrelated pairs and one group in which the word followed a neutral prime ('blanco', the Dutch equivalent for blank). The latter groups constituted the neutral conditions against which the effects of the non-neutral primes could be assessed (De Groot, 1983). Also 120 pseudoword targets were included. Half of these were preceded by the neutral prime and half by a word prime. A trial started with the presentation of a fixation star $(100 \mathrm{~ms})$ which was replaced by the prime, which remained on the screen for $17 \mathrm{~ms}$. The prime was replaced by a masking signal (XXXX) for $170 \mathrm{~ms}$ in order to prevent conscious perception of the prime. The target appeared slightly below the position where the prime had been and remained on the screen until the subjects responded. Subjects were instructed to decide, as quickly and as accurately as possible, whether the second string of each pair was a Dutch word. They were also told that they probably would not be able to read the first string. Data were collected from a two-button response panel with keys for the left index finger (no-key) and the right index finger (yes-key). After each block of 30 trials, feedback was given about the number of errors and mean RT.

\section{Strategic semantic priming task}

The procedure was taken from De Groot (1984). There were three groups of prime-target pairs, 120 in total: one group of related word pairs, one group of unrelated word pairs and one group in which the word followed a neutral prime. Eighty per cent of the prime-word pairs were related, in order to induce expectancy. Also 120 prime-pseudoword pairs were included. Half of them were preceded by a neutral prime and half by a word prime. A trial started with a fixation star which was immediately replaced by the prime. The prime was presented for $200 \mathrm{~ms}$, then the screen remained blank for $500 \mathrm{~ms}$, subsequently the target was presented. Subjects were instructed to decide, as quickly and as accurately as possible, whether the second string of each pair was a Dutch word. They were also told that the first string would be either the word 'blank' or any other word, and they were asked neither to respond overtly to this string nor to ignore it.

\section{Levels-of-processing task}

To induce the subject to encode the word on a particular level, four types of statements were presented in the initial encoding phase. Thirty-two trials were given; eight target words represented one out of the four levels. The target words of the four levels were matched for word frequency (Uit den Boogaart, 1975), number of syllables and imagery (Van Loon-Vervoorn, 1985). The four statement levels were: (1) an analysis of the orthographic structure (e.g. the first letter of the word is a ' $p$ 'page); (2) a phonemic level of analysis was induced by making judgements about the word's rhyming characteristics (e.g. the word rhymes with 'house'-mouse); (3) a semantic category analysis was required by making categorical judgements (e.g. it is a bird-starling); (4) a content semantic analysis was required by judging the meaning of the word (e.g. it tells the time-watch). For each level of encoding, half of the questions were designed to elicit 'yes' responses and half to elicit 'no' responses. Statement levels and response types were randomized. Subjects were informed that the task concerned perception. Each statement was presented on a computer screen for $2 \mathrm{~s}$, prior to the presentation of the target. The subject had to answer whether the statement was true by pressing the 'yes' or 'no' button. Answers and response times were recorded. Subjects were unexpectedly requested to recall as many words as possible from those they had just been shown, after a brief rest period. Subsequently, they were given a recognition task in which the 32 target words were randomly presented among 32 distractor words. Distractor words were matched with the target words for frequency, imagery and number of syllables.

\section{Organized word lists}

The stimulus materials consisted of three lists of 16 words. High and low frequency instances for the related lists represented instances of four categories, taken from category frequency norms (Van Loon-Vervoorn and Pijpers-Kooiman, 1988). The categories used were: clothes, tools, spices and fruits. Words were grouped according to semantic category (category-blocked condition) in the first list, and in a second list the same words were presented in a random order (category-random condition). Words that could not be categorized in semantic categories were presented (unrelated-random condition) in the third list. Word lists were matched for word frequency, imagery, number of letters and number of syllables. Words were presented sequentially for $2 \mathrm{~s}$ each on a computer screen. Two lists were presented to each subject, the unrelated word list and one of the two related lists. Subjects were asked to recall as many words as possible immediately after list presentation. The order of the lists was counterbalanced across subjects. Subjects were not informed about the categorical composition of the list. 


\section{Word fluency}

Subjects were instructed to name out loud as many instances of the categories furniture and musical instruments as they could think of. There was no time limit, but the task was stopped when the subjects did not produce a new category exemplar during $30 \mathrm{~s}$ (procedure according to Deelman and Saan, 1990). The number of words produced and the time needed to perform the task were registered. Two fluency tasks were performed, one category before and one category after substance administration. Half of the subjects started with the category furniture, the other half with the musical instruments.

\section{Choice reaction time task}

Two hundred and ten patterns of three, four or five dots were presented sequentially on a Macintosh computer screen. The task was a computer version of the Bourdon cancellation task (Bruggemans, Eling and Jansen, 1990). The subject was instructed to react by pushing the yes-button, when a four-dot pattern was presented, and by pushing the no-button in the case of three or five dots. Half of the stimuli were designed to elicit 'yes' responses and half to elicit 'no' responses. A new stimulus appeared immediately after a response. Subjects were instructed to respond as quickly and as accurately as possible. Reaction times and responses were registered.

\section{Profile of mood states (POMS)}

Subjects rated their feelings on a 5-point scale. Five factors can be extracted from the $\mathbf{3 2}$ items: tension, depression, anger, vigour and fatigue (Wald and Mellenbergh, 1990). The POMS was administered both before and after substance administration.

\section{Results}

In all ANOVAs, group (placebo or diazepam) was considered as between-subjects factor. ANOVAs were performed on the mean RTs of correct responses in the repetition priming task, the semantic priming tasks and the choice reaction time task. RTs longer than four times the standard deviation above the mean of a subject were scored as errors.

\section{5-Word lists}

Firstly, it was determined whether a memory impairment was found after diazepam intake. An ANOVA was performed on the number of correctly recalled words (see Fig. 1) with time (pre- or post-drug) and interval (immediate, $10 \mathrm{~min}$ and $30 \mathrm{~min}$ recall) as within-subjects factors, in order to establish whether diazepam induced an impaired recall. Significant main effects were found for group $[F(1,37)=11.68, p<0.005]$, time $[F(1.37)=15.28, p<0.0005]$ and interval $[F(2,37)=111.25$, $p<0.0005]$. Since subjects who ingested diazepam already recalled slightly fewer words in the pre-drug condition, an ANOVA was performed on the percentage recall, defined as percentage of the immediate recall in the pre-drug condition. This ANOVA yielded significant effects for time $[F(1,37)=11.98, \quad p<0.005]$, interval $[F(2,37)=116.82$, $p<0.0005]$ and time $\times$ interval $[F(1,37)=21.35, p<0.0005]$. However, the time $\times$ group interaction was not significant.

To investigate the relative rate of forgetting, recall after $10 \mathrm{~min}$ was expressed as a percentage of the direct recall, and the recall after $30 \mathrm{~min}$ was expressed as a percentage of the

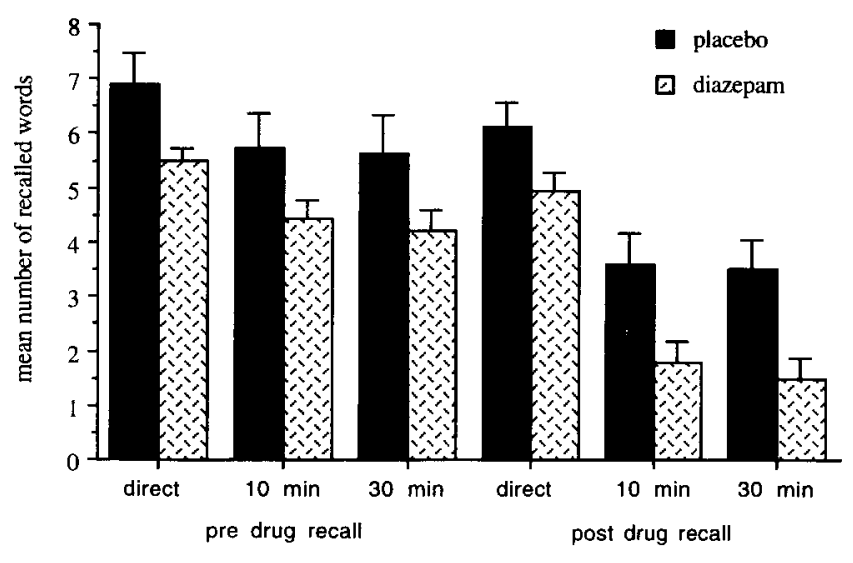

Figure 1 Mean recall (with standard errors) on the 15-word list tasks

10 min delayed recall (see Table 6). An ANOVA with time and interval as within-subjects factors yielded significant main effects of group $[F(1,37)=7.17, p<0.05]$, time $[F(1,37)=22.61$, $p<0.0005]$ and interval $[F(1,37)=33.72, p<0.0005]$. The diazepam group forgot relatively more words than the placebo group. As can be seen in Fig. 1, more forgetting occurs between the direct recall and the $10 \mathrm{~min}$ recall than between the 10 and 30 min delayed recall. Also, forgetting occurred more in the post-drug condition compared with the pre-drug condition. The group $\times$ time interaction $[F(1,37)=4.71, p<0.05]$ showed that the diazepam group forgot relatively more words in the postdrug condition compared to the placebo group. This implies that the delayed recall was impaired after diazepam intake when controlled for differences in the direct recall. Finally a time $\times$ interval $[F(1,37)=6.95, p<0.05]$ interaction was found. This did not interact with group.

To assess retrieval deficits, an ANOVA with list (pre- or postdrug list) as within-subjects factor was performed on the number of words recalled of those lists at the end of the experiment. No main effects were found, but the group $\times$ list interaction was significant $[F(1,37)=9.10, p<0.005]$. In the placebo group, recall was better for the post-drug list, while in the diazepam group the recall of the pre-drug list was better. The latter finding implies that there is no evidence for a retrieval deficit after diazepam ingestion.

\section{Repetition priming task}

To assess the repetition priming effect, an ANOVA was performed with word-condition (first presentation, repeated presentation) as within-subject factor (see Table 2). A significant word-condition effect was found $[F(1,35)=12.21, p<0.005)$ : the RT was shorter for previously presented words. No significant group effect was found, but there was a significant word-condition $\times$ group interaction effect $[F(1,35)=4.20, p<0.05]$. Post-hoc tests yielded a significant priming effect in the placebo group (Newman-Keuls $p<0.01$ ), but no priming effect in the diazepam group. An ANOVA with group as between-subjects and word-condition (first presentation, new words) as within-subject factor showed that the repetition priming effect was not due to practice, because lexical decisions for the newly presented words in the second list were not made faster than in the first presentation. Additionally, no repetition or practice effects were found for pseudowords. ANOVAs on number of errors yielded no significant effects. 
Table 2 Mean reaction times in ms (standard error in brackets) in the repetition priming task

\begin{tabular}{lccccccc}
\hline & \multicolumn{3}{c}{ Words } & & & \multicolumn{2}{c}{ Pseudowords } \\
\cline { 2 - 3 } & $\begin{array}{c}\text { 1st } \\
\text { presentation }\end{array}$ & $\begin{array}{c}\text { Repeated } \\
\text { presentation }\end{array}$ & New & & $\begin{array}{c}\text { 1st } \\
\text { presentation }\end{array}$ & $\begin{array}{c}\text { Repeated } \\
\text { presentation }\end{array}$ & New \\
\hline Placebo & $579(15)$ & $540(12)$ & $570(13)$ & & $638(16)$ & $622(18)$ & $623(15)$ \\
Diazepam & $588(21)$ & $578(26)$ & $594(25)$ & & $645(21)$ & $659(25)$ & $650(21)$ \\
\hline
\end{tabular}

\section{Automatic semantic priming task}

The RTs per prime-word condition were analysed with an ANOVA with prime-type (related, unrelated and neutral) as within-subject factor (see Table 3 ). Significant main effects were found for group $[F(1,37)=4.50, p<0.05]$ and prime-type $[F(2,37)=30.20, p<0.0005]$. RTs were longer in the diazepam group. RTs were shorter for the related word pairs compared with unrelated (Newman-Keuls, $p<0.05$ ) and neutral word pairs (Newman-Keuls, $p<0.01$ ). RTs in the unrelated word condition were shorter than those in the neutral condition (Newman-Keuls, $p<0.01$ ). A group effect $[F(1,37)=12.77$, $p<0.005]$ and an effect of prime-type $[F(1,37)=6.14, p<0.05]$ were found for the pseudoword targets. RTs were shorter after a neutral prime than after a word prime. With respect to the number of errors of the prime-word pairs, no significant difference was found between the placebo and diazepam group. However, it appears that more errors were made in the neutral condition than in the related and unrelated conditions. This suggests that the differences in RTs between the three types of prime-word pairs are not due to a speed-accuracy trade-off strategy.

\section{Strategic semantic priming task}

An ANOVA was performed with prime-type (related, unrelated and neutral) as within-subject factor and group as betweensubjects factor (see Table 4). A nearly significant group effect was found $[F(1,35)=4.07, p=0.0514]$ and a main effect of prime-type $[F(2,35)=20.87, p<0.0005]$. Subjects reacted faster to the related word pairs compared with the unrelated (NewmanKeuls, $p<0.01$ ) and neutral word pairs (Newman-Keuls, $p<0.01)$. For both substance groups, a semantic priming effect was found, but no inhibition effect. In an ANOVA on the RTs of the pseudowords, a group effect was obtained $[F(1,37)=6.66, p<0.05]$, but no effect of prime was found. An analysis on the error data yielded no significant group difference, apart from an effect of prime $[F(2,35)=9.44$, $p<0.0005]$. In the unrelated and neutral condition, more errors were made compared to the related condition (NewmanKeuls $p<0.01$ ). Therefore, the differences in RTs between the three types of prime-word pairs were not due to a trade-off between speed and accuracy.

\section{Levels-of-processing task}

Separate ANOVAs were carried out on the different dependent variables: decision times, number of recalled words, number of recognized words and false alarms. Group was the betweensubjects factor and level the within-subjects factor. Significant main effects for group $[F(1,38)=13.29, p<0.001]$ and level $[F(3,38)=5.44, p<0.005]$ were found on the decision times (see Table 6). The diazepam group took longer to make a judgement. Also an interaction between group and level was found $[F(3,38)=2.95, p<0.05]$. Post-hoc tests yielded no differences between the levels in the placebo group. However, in the diazepam group, a difference was found between the decision time for making a category judgement and other judgements. Both groups performed the decision task near ceiling level; an error was made only rarely.

An ANOVA on the number of recalled words yielded a significant effect of level $[F(3,38)=15.79, p<0.0005]$, but no significant group effect or interaction. Retention was higher for semantically and categorically processed words than for words processed phonetically or orthographically [Newman-Keuls, $p<0.05)$. An analysis on the number of recognized words showed an effect of level $[F(3,38)=114.37, p<0.0005]$. Posthoc tests showed that recognition was higher for semantically and categorically processed words than for phonetically or orthographically processed words. No group effect was found on the number of falsely recognized words (false alarms).

\section{Organized word lists}

An ANOVA with group (placebo or diazepam) and category-condition (category-blocked or category-random) as between-subjects factors and list (related and unrelated) as within-subjects factor was performed on the number of words

Table 3 Mean reaction times in ms (standard error in brackets) in the automatic semantic priming task

\begin{tabular}{lcccccc}
\hline & & Word targets & & \multicolumn{2}{c}{ Pseudoword targets } \\
\cline { 2 - 4 } \cline { 6 - 7 } Prime & Related & Unrelated & Neutral & & Word & Neutral \\
\hline Placebo & $569(15)$ & $582(14)$ & $622(15)$ & & $690(14)$ & $671(13)$ \\
Diazepam & $610(19)$ & $634(17)$ & $671(20)$ & & $772(22)$ & $766(20)$ \\
\hline
\end{tabular}

Table 4 Mean reaction times in ms (standard error in brackets) in the strategic semantic priming task

\begin{tabular}{|c|c|c|c|c|c|}
\hline \multirow[b]{2}{*}{ Prime } & \multicolumn{3}{|c|}{ Word targets } & \multicolumn{2}{|c|}{ Pseudoword targets } \\
\hline & Related & Unrelated & Neutral & Word & Neutral \\
\hline $\begin{array}{l}\text { Placebo } \\
\text { Diazepam }\end{array}$ & $\begin{array}{l}503(20) \\
600(44)\end{array}$ & $\begin{array}{l}580(16) \\
647(36)\end{array}$ & $\begin{array}{l}568(18) \\
660(38)\end{array}$ & $\begin{array}{l}609(18) \\
720(43)\end{array}$ & $\begin{array}{l}623(19) \\
724(30)\end{array}$ \\
\hline
\end{tabular}


Table 5 Mean number recalled words (standard error in brackets) of the organized word lists

\begin{tabular}{lccc}
\hline & & Related & Unrelated \\
\hline Placebo & category-random & $10.2(0.9)$ & $7.4(0.6)$ \\
& category-blocked & $11.9(0.7)$ & $7.0(0.6)$ \\
Diazepam & category-random & $7.4(0.6)$ & $5.8(0.6)$ \\
& category-blocked & $8.6(0.8)$ & $5.5(0.5)$ \\
\hline
\end{tabular}

recalled (see Table 5). Recall was better in the placebo group $[F(1,37)=15.29, p<0.0005]$. An effect of list was found $[F(1,37)=82.36, p<0.0005]$; recall was better on the related lists than on the unrelated list. A significant group $\times$ list interaction was found $[F(1,37)=4.82, p<0.05]$. Post-hoc tests yielded a significant effect (Newman-Keuls, $p<0.05$ ) of list for both substance groups and significant effects of group $(p<0.005)$ for both list conditions. Thus, subjects did benefit to a lesser extent from the relatedness of the words, after diazepam intake. Additionally a list $\times$ category-condition interaction was found $[F(1,37)=6.94, p<0.05]$. The category-blocked list was recalled better than the category-random word list (Newman-Keuls, $p<0.05$ ). No difference between the unrelated word list in the two category conditions was found.

To examine the effects of organizational processes on recall, the degree of clustering was calculated, based on the number of contiguous repetitions of same-category items divided by the total number of recalled words. An ANOVA with group and list (related-blocked and related-random) as between-subjects factor, yielded no effect of group but only a main effect of list $[F(1,37)=12.78, p<0.005]$. Clustering occurred more often after the presentation of the related-blocked word list than the relatedrandom list. No interaction between group and list was found.

\section{Word fluency}

An ANOVA with condition (pre-drug and post-drug) as withinsubject factor and group as between-subject factor was performed on the number of words. No significant group or condition effect was found. The total time used to produce words (see Table 6) as well as the mean time per item did not differ between the two groups.

\section{Choice reaction time task}

An ANOVA with group (placebo or diazepam) as betweensubjects factor, showed no significant group effect on the mean RTs (see Table 6). Also no differences in mean number of errors were found.

\section{Profile of mood states}

Mood factor scores were analysed separately with an ANOVA with group as between-subjects factor and time (pre- or post-drug) as within-subjects factor (see Table 6). On the mood factor 'fatigue' a main effect of time $[F(1,38)=31.02, p<0.0005]$ was obtained: subjects felt more fatigued after substance administration. Also an interaction was found $[F(1,38)=9.67$, $p<0.005$ ]; before drug intake no difference between groups was found, but after substance administration the diazepam group felt more fatigued than the placebo controls (Newman-Keuls, $p<0.05$ ). For the mood factor 'vigour' only a main effect of time was found $[F(1,38)=16, p<0.0005]$; subjects felt less vigorous after substance administration. No effects were found for the other mood factors.

Table 6 Performance on the different tasks (standard error in brackets)

\begin{tabular}{|c|c|c|c|c|}
\hline & \multicolumn{2}{|c|}{ Placebo } & \multicolumn{2}{|c|}{ Diazepam } \\
\hline & Pre-drug & Post-drug & Pre-drug & Post-drug \\
\hline \multicolumn{5}{|l|}{ 15-word lists ${ }^{\mathrm{a}}$} \\
\hline $\begin{array}{l}\% \text { recall } 10 \mathrm{~min} \\
\% \text { recall } 30 \mathrm{~min}\end{array}$ & $\begin{array}{l}80(4) \\
97(6)\end{array}$ & $\begin{array}{l}57(6) \\
91(5)\end{array}$ & $\begin{array}{l}79(6) \\
91(6)\end{array}$ & $\begin{array}{c}33(7) \\
60(11)\end{array}$ \\
\hline \multicolumn{5}{|l|}{ Recall pre-drug } \\
\hline 15-word list & & $2.1(0.7)$ & & $3.5(0.5)$ \\
\hline Recall post-drug list & & $3.5(0.5)$ & & $1.5(0.4)$ \\
\hline \multicolumn{5}{|c|}{ Levels-of-processing task: decision times in ms } \\
\hline $\begin{array}{l}\text { Orthographic } \\
\text { Phonemic } \\
\text { Category } \\
\text { Content semantic }\end{array}$ & & $\begin{array}{l}950(48) \\
964(61) \\
997(72) \\
961(60)\end{array}$ & & $\begin{array}{c}1123(49) \\
1218(58) \\
1432(108) \\
1198(57)\end{array}$ \\
\hline
\end{tabular}

Levels-of-processing task: percentages of words recalled according to initial level of processing

Orthographic

12 (4)

$15(5)$

$40(5)$

$18(5)$

Phonemic

33 (4)

$12(3)$

Category

$32(7)$

Content semantic

$37(5)$

Word fluency

Number of words

Total production

time

19 (2)

$21(1)$

$18(2)$

19 (2)

$129 \mathrm{~s}$

$117 \mathrm{~s}$

$92 \mathrm{~s}$

$105 \mathrm{~s}$

Choice reaction time task

Mean reaction time

in $\mathrm{ms}$

$616(17)$

$660(21)$

POMS factors

Depression

Anger

Fatigue

Vigour

Tension and the recall after $30 \mathrm{~min}$ was expressed as percentage of the $10 \mathrm{~min}$ delayed recall.

\section{Discussion}

The purpose of this study was to examine the possible loci of diazepam effects in a chain of encoding processes involved in learning a word list. Firstly, we established whether there was an effect of diazepam on memory. Then, we determined whether memory representations were activated and whether this activation spreads automatically and strategically to semantically related representations. Furthermore, we investigated whether the benzodiazepine-induced memory impairments are due to a failure to encode semantic aspects of words. Finally, it was examined whether diazepam subjects use semantic information in strategies (clustering) to guide encoding.

The diazepam subjects showed an impairment in memory; although not significant in the direct recall of the 15-word list, it was evident in the delayed recall when controlled for differences in direct recall. Furthermore, a reduced recall in the diazepam group was found on the organized word lists. In the delayed recall of the $\mathbf{1 5}$-word list, the contribution of short-term memory is eliminated and the diazepam subjects performed even more poorly. This was concluded previously by Mewaldt, Hinrichs and Ghoneim (1983). Thus, in line with previous research, memory was impaired after diazepam intake. 
However, in the 15-word list task the diazepam subjects already recalled fewer words in the pre-drug condition than the placebo controls. The reason for this pre-drug difference is unknown because subjects were assigned randomly to the groups. As expected, the difference in delayed recall between the groups was larger in the post-drug condition than in the pre-drug condition (see Fig. 1). However, the interaction was not statistically significant. This absence of significance could not be ascribed to specific subjects or floor effects. However, it does not compromise the interpretation of the results on the encoding tasks, as we did find memory impairments in the delayed recall of the 15-word list. An ANCOVA on the recall of the organized word lists, with the pre-drug direct recall of the 15-word list as covariate, still yielded a significant effect of group $[F(1,36)=9.90$, $p<0.005]$. Thus the memory impairments on the organized word lists cannot be explained by the pre-drug difference.

Retrieval from the pre-drug 15-word list and retrieval from semantic memory, as measured by word fluency, was normal after diazepam intake. Therefore the memory impairment cannot be attributed to retrieval deficits. Absolute forgetting rate was identical for both groups, but relative forgetting rate was higher after diazepam administration. However, the comparison of forgetting rates when the initial levels of recall differ, still remains a problem. Nearly all forgetting in both groups occurred in the first $10 \mathrm{~min}$ after list presentation. Thus, evidence that diazepam affects the rate of forgetting is ambiguous. After $10 \mathrm{~min}$ almost no more forgetting occurred. As in Brown et al. (1982), there was some evidence that diazepam does not affect consolidation after $10 \mathrm{~min}$ have elapsed since word presentation.

The repetition priming task was used to investigate activation of memory representations. Repetition priming did occur after placebo administration, but not after diazepam administration. In other studies (Fang, Hinrichs and Ghoneim, 1987; Danion et al., 1989, 1990; Sellal et al., 1992), it was found that diazepam did not affect repetition priming. However, in all these studies, repetition priming was assessed using a word or stem completion task, while in the present study a lexical decision task was used. The apparently discordant results might reflect a qualitative or quantitative difference between the two procedures. In our task, not only was the same stimulus repeated, but also the same response, i.e. a lexical decision was required. However, in the stem completion task used in other studies (Fang, Hinrichs and Ghoneim, 1987; Danion et al., 1989, 1990; Sellal et al., 1992), a different response to a different stimulus was required. First, subjects had to rate how much they liked or disliked a word, then the first three letters of a word were presented and subjects were asked to complete the stem to form the first word that came to mind. Knopman (1991) found a dissociation between the effects of lorazepam in a stem completion and a tachistoscopic word identification task. Schacter (1987) argued that dissociations are often observed between different priming tasks, but there is no theoretical explanation for these differences. Caution is needed in interpreting the result in the repetition priming experiment, because no direct comparison has yet been made between different repetition priming procedures after diazepam intake. In fact, in a subsequent experiment, we did find a significant repetition priming effect after ingestion of diazepam, using a word stem completion task (Gorissen et al., in preparation).
The next step was to investigate automatic and strategic spreading of activation. In both the automatic and the strategic semantic priming tasks, a priming effect was obtained for both the placebo and the diazepam group. Semantic access was not affected by diazepam because a semantic priming effect was found and because the performance on the word fluency task was not impaired after diazepam ingestion. The latter result has been reported previously (Curran, Schiwy and Lader, 1987; Ghoneim and Mewaldt, 1990; File, Sharma and Shaffer, 1992; Sellal et al., 1992). However, to our knowledge, no single study has been done on the effects of BZD on semantic priming.

With the levels-of-processing task we determined whether words were encoded semantically, and with the organized word lists whether diazepam subjects used semantic information for organizational purposes. Recall and recognition were better for semantically encoded words in the levels-of-processing task. This pattern was similar for the diazepam and the placebo group. Curran et al. (1988) also found a normal levels-of-processing effect after lorazepam and oxazepam administration. In the organized word list task, both groups clustered to improve recall, but the diazepam group did not profit as much from the categorical composition of the list as did the placebo group. These data suggest that semantic encoding takes place after diazepam intake and semantic information is used for mnemonic organization. The fact that diazepam subjects did not benefit to the same extent from the relatedness of the words might be explained as a reduced use of strategies in learning a word list. Frith et al. (1984) also found that diazepam subjects could compensate for their memory deficit by attending to semantic properties of the material. However, the diazepam subjects took less advantage of the semantic relatedness of words than did placebo controls.

Taken together, no clear evidence was found that one particular encoding process was affected after diazepam intake. But, in the repetition priming task, the semantic priming tasks, the decision part of the levels-of-processing task and the choice reaction time task, longer response times were found in the diazepam group. Although these differences did not always reach significance, the pattern was remarkably consistent. Impairments of psychomotor performance has been frequently reported to be a consequence of BZD intake (Curran, Schifano and Lader, 1991; Ghoneim, Mewaldt and Hinrichs, 1984), but it is not clear what the consequences of this slowing down are for memory processes. It seems that an increase in reaction time is more evident in complex tasks. In the levels-of-processingtask diazepam subjects were also slower than the placebo subjects. This difference was even larger when category judgements were made. Curran et al. (1988) also found that the decision times of the BZD subjects were disproportionately longer for semantic judgements in comparison to phonetic and orthographic questions. They raised the question of whether subjects on BZD simply require more time to process information deeply. One might speculate that this also has implications for organizational processes. Subjects can organize word lists, but do not have enough time to organize lists optimally when they have to perform under time pressure. The rate of presentation of words might be manipulated to investigate the relationship between slowing down of encoding operations and memory. It might be that no group effect has been found in the recall of the levels-of-processing task because 
the diazepam group took more time to study the words than the placebo group

Testing continued over a period of $\sim 2 \mathrm{~h}$ after drug ingestion. Since almost all tasks were verbal, this might give rise to interference effects. Curran et al. (1993) found that subjects were more sensitive to interference after lorazepam intake. This might also be the case after diazepam intake. It is unclear whether interference influenced the results in the different priming tasks in the present study. In tasks which required recall of words, the diazepam group did not make more intrusions than the placebo group. Additionally, if the diazepam group was more sensitive to interference, one would expect this to occur more often in the later part of the test day. However, there was again no indication that the diazepam group made more prior list intrusions in the later part. It appears that there are no strong indications that interference effects can explain the diazepam-induced memory impairments. Interference effects may also be contaminated by fatigue effects due to extensive testing, and fatigue effects might also interact with group. The diazepam group felt more fatigued after substance administration, but this was measured soon after drug intake and does not necessarily refer to fatigue due to prolonged testing. Moreover, there was no trend for an increase in reaction times in the diazepam group as the experiment wore on. Therefore, we do not think that fatigue and interference effects are an obvious explanation for the diazepam-induced memory impairments.

To summarize, a memory impairment was found after diazepam administration. This impairment is not due to retrieval deficits and is unlikely to be due to a consolidation deficit. A chain of encoding operations, employed during acquisition, was investigated. Semantic priming and semantic encoding were not affected by diazepam. A general slowing down of processes was found in the diazepam group, but its implications for memory are not completely clear. The repetition priming effect was not found after diazepam intake. This seems to be in contrast with the literature, but no firm conclusions can be drawn because different priming procedures have been used. Finally, diazepam subjects benefited less from the opportunity to organize word lists than placebo controls. It is suggested that this might be secondary to a general slowing down of information processing. Subjects do organize lists of words after diazepam intake, but are too slow to benefit from it to the same extent as the placebo controls. Not all encoding operations were investigated in this experiment, therefore it is possible that other encoding operations, such as encoding of contextual information (Brown, Brown and Bowes, 1983; Brown and Brown, 1990; Frith et al., 1984) and rate of rehearsal (Rich and Brown, 1992) are affected by diazepam.

\section{Acknowledgements}

We express our thanks to Petra Ermens and Eduard van Wijk who assisted in testing the subjects. We also express our thanks to Annette de Groot for providing the software for the priming experiments and to Michael D. Rugg and Michael G. H. Coles for their helpful comments on the manuscript. The research reported in this paper was given clearance by the Medical Ethical Committee of the Nijmegen University Hospital, CEOM number: 9106-4078.

\section{Address for correspondence}

M. Gorissen

NICI

Department of Psychology

P. O. Box 9104

6500 HE Nijmegen

The Netherlands

\section{References}

Bousfield W A (1953) The occurrence of clustering in recall of randomly arranged associates. J Gen Psychol 49: 229-240

Brown J, Brown M W (1990) The effects of repeating a recognition test in lorazepam-induced amnesia: evidence for impaired contextual memory as a cause of amnesia. Q J Exp Psychol 42A: 279-290

Brown J, Lewis V, Brown M, Horn G (1982) A comparison between transient amnesias induced by two drugs (diazepam or lorazepam) and amnesia of organic origin. Neuropsychologia 20:55-70

Brown J, Brown M W, Bowes J B (1983) Effects of lorazepam on rate of forgetting, on retrieval from semantic memory and on manual dexterity. Neuropsychologia 21: 501-512

Bruggemans C, Eling P, Jansen R (1990) Een nieuwe maat voor de diagnostiek van aandachtsstoornissen (A new measure to diagnose attention deficits). Ned Tijdschr Psychol 45: 206-213

Coenen A M L, Van Poppel H C A J M, Gribnau F W J, Vossen J M H, Van Luytelaar E L J M (1989) Benzodiazepines and cognition: effects on intentional and incidental learning. In Horne J. (ed.), Sleep '88. Gustav Fischer Verlag, Stuttgart, pp. 202-204

Craik F I M, Lockhart R S (1972) Levels of processing: a framework for memory research. J Verbal Learn Verbal Behav 11: 268-294

Curran H V (1986) Tranquillising memories: a review of the effects of benzodiazepines on human memory. Biol Psychol 23: 179-213

Curran H V, Schiwy W, Lader M (1987) Differential amnesic properties of benzodiazepines: a dose-response comparison of two drugs with similar elimination half-lives. Psychopharmacology 92: 358-364

Curran H V, Schiwy W, Eves F, Shine P, Lader M (1988) A 'levels of processing' study of the effects of benzodiazepines on human memory. Hum Psychopharmacol 3: 21-25

Curran H V, Schifano F, Lader M (1991) Models of memory dysfunction? A comparison of the effects of scopolamine and lorazepam on memory, psychomotor performance and mood. Psychopharmacology 103: 83-90

Curran H V, Gardiner J M, Java R I, Allen D (1993) Effects of lorazepam upon recollective experience in recognition memory. Psychopharmacology 110: 374-378

Danion J, Zimmerman M, Willard-Schroeder D, Grangé D, Singer L (1989) Diazepam induces a dissociation between explicit and implicit memory. Psychopharmacology 99: 238-243

Danion J, Zimmerman M, Willard-Schroeder D, Grangé D, Welsch M, Imbb J L, Singer L (1990) Effects of scopolamine, trimipramine and diazepam on explicit memory and repetition priming in healthy volunteers. Psychopharmacology 102: 422-424

Deelman B G, Saan R J (1990) Memory deficits; assessment and recovery. In Deelman $B$, Saan A, van Zomeren A (eds), Traumatic brain injury. Swets \& Zeitlinger, Lisse, pp. 49-76

De Groot A M B (1983) The range of automatic spreading activation in word priming. J Verbal Learn Verbal Behav 22: 417-436

De Groot A M B (1984) Primed lexical decision: combined effects of the proportion of related prime-target pairs and the stimulusonset asynchrony of prime and target. Q J Exp Psychol: Hum Exp Psychol 36A: 253-280

Fang J C, Hinrichs J V, Ghoneim M M (1987) Diazepam and memory: evidence for spared memory function. Pharmacol, Biochem Behav 28: 347-352 
Feustel T C, Shiffrin R M, Salasoo A (1983) Episodic and lexical contributions to the repetition effect in word identification. J Exp Psychol: Gen 112: 309-346

File S E, Sharma R, Shaffer J (1992) Is lorazepam-induced amnesia specific to the type of memory or the task used to assess it? J Psychopharmacol 6: 76-80

Frith C D, Richardson T E, Samuel M, Crow T J, McKenna P J (1984) The effects of intravenous diazepam and hyoscine upon human memory. Q J Exp Psychol 36A: 133-144

Ghoneim M M, Mewaldt S P (1990) Benzodiazepines and human memory: a review. Anesthesiology 72: 926-938

Ghoneim M M, Mewaldt S P, Hinrichs J V (1984) Behavioral effects of oral versus intravenous administration of diazepam. Pharmacol, Biochem Behav 21: 231-236

Johnson M K, Hasher L (1987) Human learning and memory. Annu Rev Psychol 38: 631-668

Johnson M K, Hirst W (1992) Processing subsystems of memory. In Lister R G, Weingartner $\mathrm{H} \mathrm{J}$ (eds), Perspectives on cognitive neuroscience. Oxford University Press, New York, pp. 197-217

Knopman D (1991) Unaware learning versus preserved learning in pharmacologic amnesia: similarities and differences. J Exp Psychol: Learn Memory Cogn 17: 1017-1029

Masson E J, McDaniel M A (1981) The role of organizational processes in long-term retention. J Exp Psychol: Hum Learn Memory 7: $100-110$

Matilla M J, Matilla M, Aranko K (1988) Objective and subjective assessments of the effects of flupentixol and benzodiazepines on human psychomotor performance. Psychopharmacology 95: 323-328

Mewaldt S P, Hinrichs J V, Ghoneim M M (1983) Diazepam and memory: support for a duplex model of memory. Memory and Cognition 11: 557-564

Mewaldt S P, Ghoneim M M, Hinrichs J V (1986) The behavioral actions of diazepam and oxazepam are similar. Psychopharmacology 88: $165-171$

Murphy M D (1979) The measurement of category clustering in free recall. In Puff $C R$ (ed.), Memory organization and structure. Academic Press, New York

Neely J H (1977) Semantic priming and retrieval from lexical memory: roles of inhibitionless spreading activation and limitedcapacity attention. J Exp Psychol: Gen 106: 226-254
Posner M I, Snyder C R R (1975) Attention and cognitive control. In Solso R L (ed.), Information processing and cognition: the Loyola symposium. Erlbaum, Hillsdale, NJ

Rich J B, Brown G G (1992) Selective dissociations of sedation and amnesia following ingestion of diazepam. Psychopharmacology 106: $346-350$

Rodrigo G, Lusiardo M (1988) Effects on memory following a single oral dose of diazepam. Psychopharmacology 95: 263-267

Roy-Byrne P P, Uhde T W, Holcomb H, Thompson K, King A K, Weingartner $H$ (1987) Effects of diazepam on cognitive processes in normal subjects. Psychopharmacology 91: 30-33

Schacter D L (1987) Implicit memory: history and current status. J Exp Psychol: Learn, Memory Cogn 11: 501-518

Sellal F, Danion J, Kauffman-Muller F, Grangé D, Imbs J, Van der Linden M, Singer L (1992) Differential effects of diazepam and lorazepam on repetition priming in healthy volunteers. Psychopharmacology 108: 371-379

Stephens D N, Duka T, Andrews J S (1991) Benzodiazepines, betacarbolines and memory. In Weimar J, Hunter $J$ (eds), Memory, clinical and theoretical aspects. Hamwood Academic Publishers, London, pp. 11-42

Taft M (1991) Reading and the mental lexicon. Lawrence Erlbaum Associates, Hillsdale, NJ

Tweedy J R, Lapinski R H, Schvaneveldt R W (1977) Semanticcontext effects on word recognition: influence of varying the proportion of items presented in an appropriate context. Memory and Cognition 5: 84-89

Uit den Boogaart P C (ed.) (1975) Woordfrequentie in geschreven en gesproken Nederlands (Wordfrequency of written and spoken Dutch). Oosthoek, Scheltema \& Holkema, Utrecht

Van Loon-Vervoorn W A (1985) Voorstelbaarheidswaarden van nederlandse woorden (Imagery norms of Dutch words). Swets \& Zeitlinger, Lisse

Van Loon-Vervoorn W A, Pijpers-Kooiman M J (1988) Categoriefrequentienormen als maat voor typicaliteit (Category-frequency norms as measure of typicality). Ned Tijdschr Psychol 7: 335-339

Wald F D M, Mellenbergh G J (1990) Instrumenteel onderzoek: de verkorte versie van de Nederlands vertaling van de Profile of Mood States (POMS) (The shortened version of the Dutch Profile of Mood States). Ned Tijdschr Psychol 45: 86-90 